Dobson, Ms H Fiddes Mrs L McKay, Mrs E Stewart, and Ms S Swiatek for identification of patients and collection of data, and our colleagues in the Glasgow hospitals for their cooperation.

Contributors: GMT, JMcE, and CWR designed the study, ST supervised collection of the data, and GDM and KIP analysed the results. All authors contributed to the interpretation and drafting of the paper and will act as guarantors for the paper

Funding: The study was supported by the chief scientist, Scottish Health Department (grant reference No K/OPR/2/2/ D229).

Competing interests: GMT has been reimbursed by government and professional scientific bodies and commercial organisations for attending scientific symposiums. Other research into head injuries by his department has been supported by the Scottish Health Department, the Medical Research Council, and Bayer, Novartis, Parke-Davies, and Cambridge Neuroscience. The University of Glasgow has received fees on GMT's behalf for advice and consultancy work to the foregoing bodies and Pharmos, SmithKline Beecham, GlaxoWellcome, and Pfizer, and for providing reports on medicolegal cases. GMT is director of three charitable organisations: the Head Injury Trust, Scotland; the European Brain Injury Consortium; and the International Neurotrauma Society.

1 MacMillan R, Strang I, Jennett B. Head injuries in primary surgical ward in Scottish hospitals. Scottish head injury management study. Health Bull 1979;37:75-81.

2 Field JH. Epidemiology of head injuries in England and Wales. London: Research Division, Department of Health and Social Security, 1975.

3 Bryden J. How many head injuries? The epidemiology of post head injury disability. In: Wood R, Eames P, eds. Models of brain injury rehabilitation. Baltimore: John Hopkins University Press, 1989:17-26.

4 Kraus JF. Epidemiology of head injury. In: Cooper PL, ed. Head injury. 3rd ed. London: Williams and Wilkins, 1993:1-25.

5 Wade DT, Hewer RL. Epidemiology of some neurological diseases with special reference to work load on the NHS. Int Rehabil Med 1987;8:12937.

6 Rimel RW, Giordani B, Barth JT, Boll TJ, Jane JA. Disability caused by minor head injury J Neurosurg 1981:9:221-8.

7 Rimel RW, Giordani B, Barth JT, Jane JA. Moderate head injury: completing the clinical spectrum of brain trauma. J Neurosurg 1982;11:344-51.
8 Marshall LF, Becker DP, Bower SA, Cayard C, Elsenberg H, Gross CR, et al. The National Traumatic Coma Data Bank. Part 1. Design purpose goals and results. J Neurosurg 1983;59:276-84.

9 Jennett B, Bond M. Assessment of outcome after severe brain damage. A practical scale. Lancet 1975;ii:81-4.

10 Wilson JTL, Pettigrew LEL, Teasdale GT. Structured interviews for the Glasgow outcome scale and the extended Glasgow outcome scale: guidelines for their use. J Neurotrauma 1998;15:573-85.

11 McKinlay WW, Brooks DN. Methodological problems in assessing psychosocial recovery following severe head injury. J Clin Neuropsychology $1984 ; 6: 87-99$

12 Masson F, Vecsey J, Salmi LR, Dartigues JF, Erny PH, Maurette P. Disability and handicap 5 years after a head injury: a population based study. $J$ Clin Epidemiol 1997;50:595-601.

13 Corrigan JD, Bogner JA, Mysiw WJ, Clinchot D, Fugate L. Systematic bias in outcome studies of persons with traumatic brain injury. Arch Phys Med Rehabil 1997;78:132-7

14 Moss NEG, Wade DT. Admission after head injury: how many occur and how many are recorded. Injury 1996;27:159-61.

15 Relander M, Troupp H, Bjorkesten G. Controlled trial of treatment for cerebral concussion. BMJ 1972;iv:777-9.

16 Teasdale GT, Pettigrew LEL, Wilson JTL, Murray G, Jennett B. Analysing outcome of treatment of severe head injury: a review and update on advancing use of the Glasgow outcome scale. I Neurotrauma 1998; 15:587-97

17 Anderson SI, Housley A, Jones PA, Slattery J, Miller DJ. Glasgow outcome scale: an inter-rater reliability study. Brain Injury 1993;7:309-17.

18 Wade DT, King NS, Weden FJ, Crawford S, Caldwell FE. Does routine follow up after head injury help? A second randomised controlled trial. $J$ Neurol Neurosurg Psychiatry 1998:65:177-83.

19 Hellawell DJ, Taylor R, Pentland B. Cognitive and psychosocial outcome following moderate or severe traumatic brain injury. Brain Injury 1999;13:489-504

20 Tellier A, Della Malva LC, Winu AC, Grahovac S, Morrish W, Brennan Barnes M. Mild head injury, a misnomer. Brain Injury 1999;13:463-75.

21 Rice-Oxley M, Turner-Stokes L. Effectiveness of brain injury rehabilitation. Clin Rehabil 1999;13:7-24.

22 King NS, Crawford S, Wenden FJ, Moss NEG, Wade DT. Interventions and service need following mild and moderate head injury: the Oxford Head Injury Service. Clinical Rehabilitation 1997;11:13-27.

23 British Society of Rehabilitation Medicine. Rehabilitation after traumatic brain injury. A working party report of the British Society of Rehabilitation Medicine. London: BSRM, 1998.

24 Royal College of Surgeons of England. Working party on the management of patients with head injury. London: RCS, 1999.

(Accepted 15 March 2000)

\title{
US women's attitudes to false positive mammography results and detection of ductal carcinoma in situ: cross sectional survey
}

\author{
Lisa M Schwartz, Steven Woloshin, Harold C Sox, Baruch Fischhoff, H Gilbert Welch
}

\begin{abstract}
Objective To determine women's attitudes to and knowledge of both false positive mammography results and the detection of ductal carcinoma in situ after screening mammography.

Design Cross sectional survey.

Setting United States.

Participants 479 women aged 18-97 years who did not report a history of breast cancer.

Main outcome measures Attitudes to and knowledge of false positive results and the detection of ductal carcinoma in situ after screening mammography. Results Women were aware that false positive results do occur. Their median estimate of the false positive rate for 10 years of annual screening was 20\% (25th percentile estimate, $10 \%$; 75 th percentile estimate, $45 \%$ ). The women were highly tolerant of false positives: $63 \%$ thought that 500 or more false positives per life saved was reasonable and $37 \%$ would tolerate 10000 or more. Women who had had a false
\end{abstract}

positive result $(\mathrm{n}=76)$ expressed the same high tolerance: $39 \%$ would tolerate 10000 or more false positives. $62 \%$ of women did not want to take false positive results into account when deciding about screening. Only $8 \%$ of women thought that mammography could harm a woman without breast cancer, and $94 \%$ doubted the possibility of non-progressive breast cancers. Few had heard about ductal carcinoma in situ, a cancer that may not progress, but when informed, $60 \%$ of women wanted to take into account the possibility of it being detected when deciding about screening.

Conclusions Women are aware of false positives and seem to view them as an acceptable consequence of screening mammography. In contrast, most women are unaware that screening can detect cancers that may never progress but feel that such information would be relevant. Education should perhaps focus less on false positives and more on the less familiar outcome of detection of ductal carcinoma in situ.
Correspondence to:

L M Schwartz lisa.schwartz@ dartmouth.edu continued over

BMJ 2000;320:1635-40

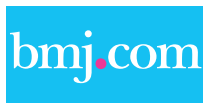

This article is part of the BMJ's randomised controlled trial of open peer review. Documentation relating to the editorial decision making process is available on the BMJ's website 
Veterans

Administration

Outcomes Group

(111B), Veterans

Administration

Medical Center,

White River

Junction, VT 05009 ,

USA

Lisa M Schwartz

assistant professor of

medicine

Steven Woloshin

assistant professor of

medicin

H Gilbert Welch

associate professor of

medicine

Department of

Medicine,

Dartmouth-Hitchock

Medical Center,

Lebanon, $\mathrm{NH}$

03756, USA

Harold C Sox

Joseph $M$ Huber

professor

Department of Social and Decision Sciences, Carnegie Mellon University, Pittsburgh, PA 15213, USA

Baruch Fischhoff professor

\section{Introduction}

Screening mammography is vigorously promoted in the United States. With the exception of the US government's Preventive Health Services Task Force, professional organisations recommend that women begin annual or biannual screening at 40 years of age. $^{1-3}$ Mammography is promulgated by hospitals, insurance plans, and breast care centres. Efforts for quality improvement commonly focus on increasing the screening rates for breast cancer, and health plans highlight these rates on cards used for reporting quality of health care. Although there has been much discussion about the potential benefit of mammography there has been far less about the potential harms.

The harm that has received the most attention is false positive results. Mammograms that give false positive results are common. A 60 year old woman screened annually for 10 years has a $50 \%$ chance of having at least one false positive leading to follow up testing and a $20 \%$ chance of a false positive leading to biopsy. ${ }^{4}$ Consequently, many people are concerned about the physical, psychological, and economic costs of false positives. ${ }^{4-10}$ Several experts in screening have concluded that women would benefit from education about false positive results if they are to make informed decisions about whether to undergo, or continue with, screening. ${ }^{211-13}$

Little attention has been paid to the increasingly frequent detection of ductal carcinoma in situ, a subtle but potential harm of screening. ${ }^{14}$ Although the clinical course of ductal carcinoma in situ is poorly understood, most lesions do not progress. ${ }^{14-17}$ Consequently, an increasing number of women with lesions that would never have become clinically apparent are worried about cancer, and most of them will undergo invasive treatment of unknown benefit (for example, mastectomy, lumpectomy with radiation). ${ }^{14}$

It is not known if or how women who are offered screening are being counselled about false positives and ductal carcinoma in situ. To determine what women know we conducted a national survey of women in the United States, a population with high exposure to mammography-more than $85 \%$ of US women aged 40 years or more have had at least one screening mammography. ${ }^{18}$ We wanted to find out if women are aware of false positives and if they have a sense of the chance of having one; if false positives are tolerated because women have an unrealistic sense of the benefit of mammography; and if women are aware of ductal carcinoma in situ and, if not, whether they want to know about it.

\section{Participants and methods}

Design

We randomly selected women from details compiled from telephone directories and administrative records (for example, applications for a driver's licence, electoral registries, house purchases) by National Decision Systems (Atlanta, GA). We restricted our sample to the $80 \%$ of US women in households with telephones. We used stratified random sampling to oversample women of screening age. Specifically, we selected women by age (18-39 years old, 200 women; 40-49, $250 ; 50-69,250 ; 70$ or older, 100), estimated income

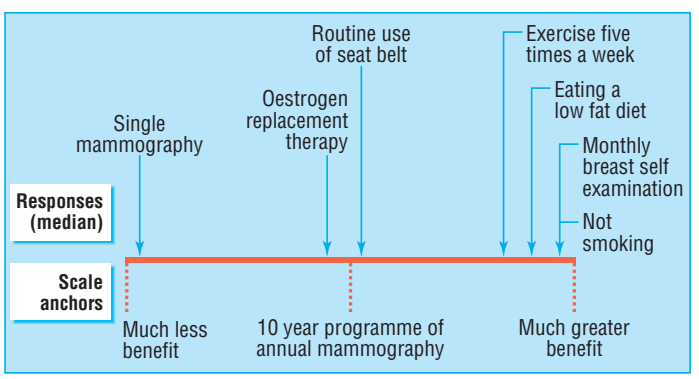

Fig 1 Women's ranking of benefits of health promoting activities and 10 year programme of mammography for extending life in a 60 year old woman. Arrows show median response for each strategy

(income more or less than twice the 1992 poverty threshold for a family of four people ${ }^{19}$ ), and area of residence.

From August to October 1997 we posted a questionnaire (with $\$ 2$ (£1.25) as an incentive) to 800 women. We chose to conduct a postal survey to utilise visual analogue scales. We posted reminder letters to non-respondents after two weeks, sent a second copy of the questionnaire after four weeks, and attempted to telephone those who had still not responded after six weeks.

Of the 800 people selected, 33 were ineligible (21 had died, 12 were male), leaving 767 possible respondents. Of these women, 55 had incorrect addresses, two did not speak English, and 207 did not return the questionnaire. Overall, 503 of the 767 women (65.6\%) returned completed questionnaires. We report on the 479 respondents with no history of breast cancer.

\section{Survey}

We developed a 13 page questionnaire as part of a larger project on women's decision making about mammography. A pilot was tested on women veterans served by the Veterans Administration Medical Center at White River Junction, Vermont.

\section{Visual analogue scales}

We asked women to estimate the sensitivity and false positive rate of mammography with a previously validated visual analogue scale. $^{20}$ To familiarise respondents with the scale, we included two practice questions about events having extreme probabilities. Overall, 94\% of respondents used the correct end of the scale for each event-close to 1 for the chance of stopping at a red light, and close to 0 for the chance of being hit by a meteorite.

We also asked women to compare the benefits of mammography with those of other preventive activities that would extend the life of a 60 year old woman (fig 1). For each prevention strategy, we asked respondents to mark anywhere on a line scaled from "much less benefit" to "much greater benefit" compared with 10 years of annual mammography, the mid-point being "same benefit." We measured the distance of each woman's mark from "much less benefit" and calculated the median value.

\section{Analysis}

Because we used stratified random sampling, we calculated sample weights to account for probability of selection and to compensate for small differences in 
Table 1 Characteristics of sample compared with women 18 years and older from the 1990 US census. Values are numbers (percentages) unless stated otherwise

\begin{tabular}{|c|c|c|}
\hline Characteristic & $\begin{array}{l}\text { Patients } \\
(\mathrm{n}=479)\end{array}$ & $\begin{array}{c}1990 \text { US census } \\
(\%)\end{array}$ \\
\hline \multicolumn{3}{|l|}{ Age (years): } \\
\hline $18-39$ & $120(25)$ & 46 \\
\hline $40-49$ & $153(32)$ & 16 \\
\hline $50-69$ & $158(33)$ & 24 \\
\hline$\geqslant 70$ & $48(10)$ & 14 \\
\hline \multicolumn{3}{|l|}{ Ethnicity: } \\
\hline White & $431(90)$ & 78 \\
\hline African-American & $19(4)$ & 11 \\
\hline Hispanic & $10(2)$ & 7 \\
\hline Other & $19(4)$ & 4 \\
\hline \multicolumn{3}{|l|}{ Household income (\$): } \\
\hline$<10000$ & $24(5)$ & 13 \\
\hline $10000-24999$ & $86(18)$ & 24 \\
\hline $25000-49999$ & $158(33)$ & 33 \\
\hline $50000-99999$ & $163(34)$ & 22 \\
\hline$\geqslant 100000$ & $48(10)$ & 8 \\
\hline \multicolumn{3}{|l|}{ Highest level of education: } \\
\hline$<$ High school graduate & $29(6)$ & 25 \\
\hline High school degree & $268(56)$ & 53 \\
\hline College degree & $139(29)$ & 17 \\
\hline Postgraduate degree & $43(9)$ & 5 \\
\hline \multicolumn{3}{|l|}{ Region: } \\
\hline North east & $67(14)$ & 21 \\
\hline Midwest & $115(24)$ & 24 \\
\hline South & $153(32)$ & 35 \\
\hline West & $144(30)$ & 20 \\
\hline
\end{tabular}

$95 \%$ confidence intervals ranged from $4 \%$ to $6 \%$ in either direction for all percentages.

response rates across sample strata. We then adjusted the sample distribution to conform to known marginal distributions of the US population based on data from the 1990 US census ${ }^{19} 21$ by creating "balance weights." ${ }^{22}$ Because the crude results and the weighted results were almost identical, for simplicity we present the crude data. Based on our sample size, we estimate the margin of error of the results to be $4-6 \%$ in either direction. ${ }^{23}$ All analyses were done with STATA software (College Station, TX).

\section{Results}

\section{Sample characteristics}

Table 1 shows the characteristics of the women. Respondents were from all 50 states and the District of Columbia. Most women reported having had at least one mammogram: $35 \%$ of women less than 40 years of age, $87 \%$ of women in their 40 s, $93 \%$ of women aged $50-69$, and $87 \%$ of women aged 70 or more. ${ }^{3}$ Similarly high proportions of women planned to have a mammogram in the next two years.

\section{Perception of harm}

Overall, $441(92.0 \%)$ women believed that mammography could not harm a woman without breast cancer (table 2). Thirty of the 40 women who thought harm was possible responded to our request for an explanation. The most common responses were exposure to radiation (16 women), stress or anxiety (four), and false positives (three). None mentioned the effects of treating non-progressive cancer.
False positive results

Overall, 99\% of women believed that false positive results occur during a 10 year programme of annual mammography beginning at age 60 years. The women's median estimated chance of a false positive during such a programme was $20 \%$. This estimate is in line with a recent report citing a $47 \% 10$ year probability of a false positive mammogram leading to any follow up testing for a 60 year old woman and a $19 \%$ probability of a false positive mammogram leading to a biopsy. ${ }^{4}$

To understand the importance of false positives, we asked respondents whether they wanted to take into account such results when deciding about mammography; only 38\% did. When asked how many false positives would be acceptable for each life saved, women showed a high tolerance: $63 \%$ would tolerate 500 or more false positives and $37 \%$ would tolerate 10000 or more (fig 2). The best estimate of the actual number of false positive mammograms for each life saved is somewhere between 30 and 200, assuming 2-6 lives saved for every 1000 women screened for 12 years $^{24}{ }^{25}$ and a 10 year false positive rate between $20 \%$ and $40 \%{ }^{4}$ Thus, the actual number of false positives is far below the number most women deemed acceptable.

Women who had had a false positive mammogram expressed a similarly high tolerance for false positive results. Seventy six women (16\%) reported having had a false positive mammogram-that is, a breast biopsy

Table 2 Women's perceptions of benefits and harms of screening

No $(\%)$ of patients

\section{Perceptions of harms}

Do you agree that "if a woman getting mammograms turns out not to have breast cancer, she may have been harmed by the mammograms"?

\section{False positives}

"Imagine a typical, healthy 60 year old woman. Assume that you know nothing else about her. Suppose that this 60 year old woman has yearly mammograms for the next 10 years and she does not have breast cancer. What is the chance that she will have a 'false alarm' where one of her mammograms will look like she has cancer even though she doesn't?"

"Is information about false alarms something you want to factor into your decision about getting a mammogram?"*

Non-progressive cancer

Do you agree that "some types of breast cancer grow so slowly that even without 34 (7) treatment they would not affect a woman's health"?

Presentation of ductal carcinoma in situ (DCIS) informationt: "Have you heard about DCIS before this survey?"*

"Is information about DCIS something you want to factor into your decision about $287(60)$ getting a mammogram?"*

Perceptions of benefits

Do you agree that "if a woman getting mammograms turns out to have breast 450 (94) cancer, she may have benefited from the mammograms"?

Sensitivity of mammography

“Imagine a typical, healthy 60 year old woman. Assume that you know nothing else Median 73/100, about her. Now imagine this 60 year old woman has breast cancer but no 25 th percentile $=50 \%$, obvious symptoms. What is the chance a mammogram will find the cancer?" $\quad 75$ th percentile $=86 \%$ Magnitude of benefit

"All things being equal, if this 60 year old woman got yearly mammograms for the next 10 years, she would have ..."

\begin{tabular}{lc}
\hline A higher or unchanged chance of dying of breast cancer & $34(7)$ \\
\hline A lower chance of dying of breast cancer: & \\
\hline By one fifth to one tenth & $62(13)$ \\
\hline By one third & $120(25)$ \\
\hline By a half & $263(55)$ \\
\hline Reduced to zero & $0(0)$ \\
\hline
\end{tabular}

$95 \%$ confidence intervals ranged from $4 \%$ to $6 \%$ in either direction for all percentages. Questions preceded by 'do you agree' used a five point Likert scale (strongly agree to strongly disagree); the proportion agreeing is those who answered "strongly agree" or "agree."

*Percentage of women answering "yes."

†Women were given a brief explanation of ductal carcinoma in situ as a lesion that does not always progress to invasive cancer. 
but no diagnosis of breast cancer. In this subgroup, $93 \%$ believed that mammography could not harm a woman who turned out not to have breast cancer, 35\% wanted to take false positives into acount when deciding on screening, $71 \%$ would tolerate 500 or more false positives per life saved, and 39\% would tolerate 10000 or more (fig 2).

\section{Perception of benefit}

To explore whether this high tolerance reflected an unrealistic sense of the benefit of mammography, we examined perceptions of benefit. As expected, most $(94 \%)$ of the women believed that women whose breast cancer was diagnosed by screening mammography benefited from having been screened (table 2). Although most believed that mammography reduced the chance of dying of breast cancer, none thought it reduced the risk to zero. The most common expectation was that mammography would reduce the chance of dying of breast cancer by half and the second most common expectation was that it would reduce the chance by one third ${ }^{24}{ }^{25}$ (we considered this to be the correct answer; however, a recent study suggests that a one third reduction in risk may be an overestimate ${ }^{26}$ ). Women were aware that mammograms did not find all cancers. Their median estimated sensitivity for a single mammogram (for a 60 year old woman) of $73 \%$ underestimated the reported sensitivity of $94 \%(95 \%$ confidence interval $83 \%$ to $99 \%) .{ }^{27}$

Most women (82\%) recognised that a 10 year programme of mammography was more beneficial than mammography performed only once (fig 1 ). Women rated health promoting strategies like not smoking, exercising regularly, and eating a low fat diet as much more beneficial than mammography. Surprisingly, women believed breast self examinations to be more beneficial than the 10 year programme of annual mammography.

\section{Non-progressive cancer}

Few women knew about the possibility of nonprogressive breast cancer (table 2). Only 7\% agreed that some breast cancers grow so slowly that even without treatment they would not affect a woman's health. We gave the following brief explanation of ductal carcinoma in situ: "We would like to ask your opinion about ductal carcinoma in situ or DCIS, a breast abnormality which can only be picked up by mammograms. Cancer

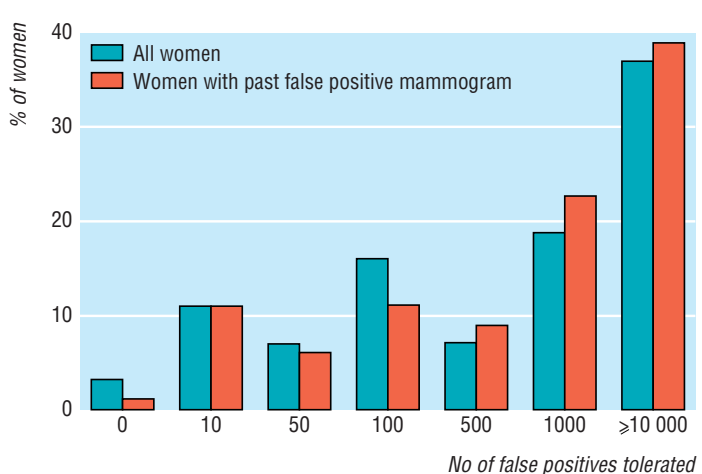

Fig 2 No of false positive results women were prepared to tolerate for each life saved

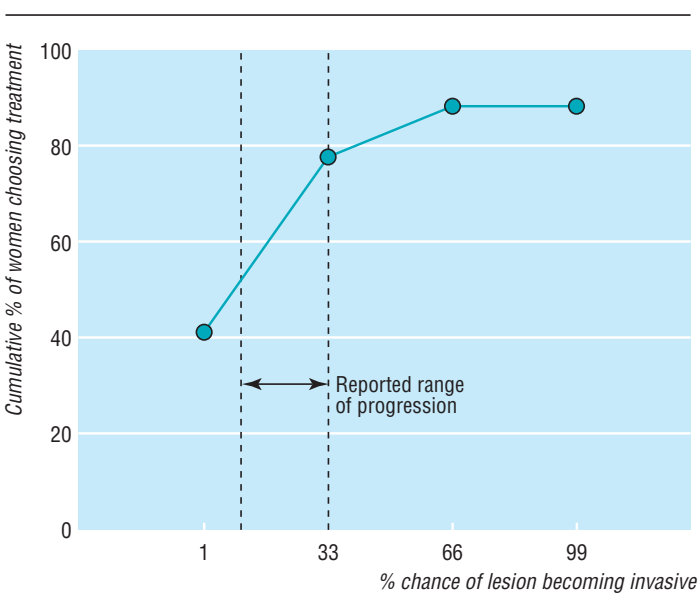

Fig 3 Women's threshold for treatment of ductal carcinoma in situ according to chance of becoming invasive

specialists are confused about DCIS because sometimes it becomes invasive and sometimes it doesn't. If DCIS does not become invasive, it will not affect how long a person will live even without treatment. Doctors don't know which DCIS will become invasive. Nowadays, almost everyone with DCIS gets treated. Many people receive surgery, chemotherapy, or radiation who would never have gotten sick. For these people, treatment provides no physical benefit."

Only $6 \%$ of women reported having heard of ductal carcinoma in situ by name or corresponding to the description provided, and $60 \%$ wanted to take ductal carcinoma in situ into account when deciding about mammography, with interest highest among younger women (71\% of women aged $18-39)$.

To assess how information about non-progressive cancer might influence decision making, we asked women to decide about treatment for ductal carcinoma in situ under different assumptions of its probability of becoming invasive (fig 3 ). In the hypothetical scenario that ductal carcinoma in situ became increasingly likely to become invasive, more women chose treatment as the chance of invasion increased. At a $1 \%$ chance of ductal carcinoma in situ becoming invasive, $42 \%$ of women chose treatment whereas at a $33 \%$ chance of invasion, $78 \%$ chose treatment. The limited published estimates of the chance of ductal carcinoma in situ becoming invasive varies and are as high as $33 \%{ }^{14}{ }^{17}$

\section{Discussion}

The women in our study were aware of false positive results from screening mammography but seemed to view them as an acceptable consequence of screening. Although studies attest to the short term physical and psychological impact of false positive results, ${ }^{5-9}$ our respondents were highly accepting of them: most would not take them into account when deciding about screening, and almost $40 \%$ would tolerate 10000 or more false positives requiring biopsy for each life saved.

One explanation for this high tolerance is that women have an overly optimistic sense of the benefit of mammography. We found no evidence to support this explanation. No respondent thought screening mam- 
mography eliminated the chance of dying of breast cancer. Women were aware that mammography misses some cancers (actually underestimating the reported sensitivity). Most women also recognised that health promoting behaviours such as not smoking, exercising regularly, and eating a low fat diet were more beneficial than mammography in prolonging life, which is true for the average 60 year old woman. ${ }^{28}$

Alternatively, it might be posited that women did not fully understand the consequences of a false positive result (for example, anxiety, pain, inconvenience, or extremely rare harms such as severe infection or death related to anaesthesia). We found, however, that women who had had false mammograms expressed the same high tolerance as women who had not. Thus, women seemed to think that false positives are worth the reassurance of being told they do not have cancer. Similarly, Gram et al found that almost half of women with false positive mammograms viewed the experience as having an overall positive impact on their lives, ${ }^{8}$ and most women continue to undergo mammography. ${ }^{29}$

Women's perceptions about a potential diagnosis of ductal carcinoma in situ differed noticeably from their perceptions about false positive mammograms. In contrast to false positives, most women were unaware of non-progressive forms of breast cancer and even doubted their existence. Once informed about non-progressive cancer, the women seemed concerned. Most wanted to take into account the possibility of ductal carcinoma in situ when deciding about screening. Younger women, in whom $90 \%$ of the cancers found by screening mammography are ductal carcinoma in situ, ${ }^{15}$ were the most interested in such information. In addition, women's reported willingness to treat ductal carcinoma in situ increased as we hypothetically increased the chance of ductal carcinoma in situ progressing to invasive breast cancer, suggesting that such information might influence decisions.

\section{Limitations}

One limitation of our study is the representativeness of the sample: we did not include women in households without a telephone and those who requested that their name be removed from the database. This left about $80 \%$ of US women eligible for sampling. Secondly, although our sample represents women across a broad range of age, education, and income, it differed from the general population: the women were wealthier and better educated, and almost all were white. Women from ethnic minorities and women with the lowest socioeconomic indicators were underrepresented. Subsequent studies are needed to assess whether such women have different perceptions.

One concern is the possibility of systematic bias in our sample because respondents differed from non-respondents. Our response rate of $66 \%$ lessens but does not eliminate this concern. Respondents and non-respondents did not differ by age (the one variable available for comparison). Our main findings were, however, extreme enough (for example, only $7 \%$ of women were aware of non-progressive breast cancer) to suggest that even if respondents and nonrespondents differed noticeably, our overall conclusions should remain robust. Although the survey was long and complex, response rates for items were high. Response rates were lowest for the question on the

\section{What is already known on this topic}

False positive results and diagnoses of non-progressive cancer are recognised problems of screening mammography

Little is known about how women feel about these problems

\section{What this study adds}

Almost all of the 479 women (99\%) knew that false positive mammograms occur

Women do not seem to think that false positive mammograms are an important harm of screening - even women who have had a false positive result

Women's tolerance of false positives is not explained by overly optimistic beliefs about the benefit of mammography

Few of the women $(6 \%)$ were aware of the possibility of non-progressive cancer

treatment threshold for ductal carcinoma in situ (82\%) and averaged $98 \%$ for all other questions.

Although experts on screening have focused much attention on the anxiety experienced by women with false positive mammograms, ${ }^{13}$ we believe clinicians counselling women about mammography should spend less time reviewing what most women know and accept-that is, that false positives are part of screening. In contrast, more time should probably be spent educating women about the less familiar outcome of the ambiguity associated with the detection of ductal carcinoma in situ.

We thank Robert Pritchard for help with the study design, $\mathrm{R}$ Peter Mogielnicki for helpful comments, and Jennifer Winder and Suzy Shukwit for assistance with data collection.

Contributors: LMS and SW collaborate on all work and are the joint principal investigators on the Department of Defense grant "enhancing informed decision making about mammography"; they will act as guarantors for the paper. They initiated and coordinated the formulation of the study hypotheses, discussed core ideas, designed the study protocol, developed the survey, and participated in the data collection, analysis, and writing of the paper. HCS and BF participated in formulating the study hypotheses, discussing core ideas, designing the study, developing the survey, and writing the paper. HGW participated in the formulation of study hypotheses, discussing core ideas, designing the study, developing the survey, the analysis, and writing of the paper.

Funding: SW and LMS are supported by the veterans affairs career development awards in health services research and development. This work was also funded by a new investigator award from the Department of Defense breast cancer research program (DAMD17-96-MM-6712). The views expressed do not necessarily represent those of the Department of Veterans Affairs or the US government.

Competing interests: None declared.

1 American Cancer Society. Summary of current guidelines for the cancer-related checkup:recommendations. New York: ACS, 1988

2 National Cancer Advisory Board. National Cancer Advisory Board mammography recommendations for women ages 40-49. Bethesda, MD: National Cancer Advisory Board, 1997.

3 US Preventive Services Task Force. Guide to clinical preventive services, 2nd ed. Baltimore: Williams and Wilkins, 1996.

4 Elmore J, Barton M, Moceri V, Polk S, Arena P, Fletcher S. Ten-year risk of false positive screening mammograms and clinical breast examinations. N Engl J Med 1998;338:1089-96.

5 Lerman C, Trock B, Rimer B, Boyce A, Jepson C, Engstrom P. Psychological and behavioral implications of abnormal mammograms. Ann Intern Med 1991;114:657-61. 
6 Sutton S, Saidi G, Bickler G, Hunter J. Does routine screening for breast cancer raise anxiety? Results from a three wave prospective study in England. J Epidemiol Community Health 1995;49:413-8.

7 Lerman L, Trock B, Rimer B, Jepson C, Brody D, Boyce A. Psychological side effects of breast cancer screening. Health Psychol 1991;10:259-67.

8 Gram I, Lund E, Slenker S. Quality of life following a false positive mammogram. Br J Cancer 1990;62:1018-22.

9 Ellman R, Angeli N, Christians A, Moss S, Chamberlain J, Maguire P. Psychiatric morbidity associated with screening for breast cancer. BrJ Cancer 1989;60:781-4.

10 Lidbrink E, Elfving J, Frisell J, Jonsson E. Neglected aspects of false positive findings of mammography in breast cancer screening: analysis of false positive cases from the Stockholm trial. BMJ 1996;312:273-6.

11 Ransohoff D, Harris R. Lessons from the mammography screening controversy: can we improve the debate? Ann Intern Med 1997;127:1029-34.

12 Fletcher S. False-positive screening mammograms: good news, but more to do. Ann Intern Med 1999;131:60-2.

13 National Institutes of Health consensus statement. Breast cancer screening for women ages 40-49. Bethesda, MD: National Cancer Institute, 1997.

14 Ernster VL, Barclay J, Kerlikowske K, Grady D, Henderson C. Incidence of and treatment for ductal carcinoma in situ of the breast. JAMA 1996:275:913-8

15 Ernster VL, Barclay J. Increases in ductal carcinoma in situ (DCIS) of the breast in relation to mammography: a dilemma. Monogr Natl Cancer Inst 1997;22:151-6.

16 Welch $\mathrm{H}$, Black W. Using autopsy series to estimate the disease "reservoir" for ductal carcinoma in situ of the breast: how much more breast cancer can we find? Ann Intern Med 1997; 127:1023-8.

17 Page D, Dupont W, Rogers L, Jensen R, Schuyler P. Continued local recurrence of carcinoma 15-25 years after a diagnosis of low grade ductal carcinoma in situ of the breast treated only by biopsy. Cancer $1995 ; 76: 1197-2000$
18 Blackman DK, Bennett EM, Miller DS. Trends in self-reported use of mammograms (1989-1997) and Papanicolaou tests (1991-1997)behavioral risk factor surveillance system. MMWR CDC Surveill Summ 1999;48:1-22.

19 US Bureau of the Census. Statistical abstract of the United States, 117th ed. Washington, DC: US Bureau of the Census, 1997.

20 Woloshin S, Schwartz LM, Byram S, Fishhoff B, Welch H. A new scale for assessing perceptions of chance: a validation study. Med Decis Making 2000. (In press.)

21 Ruggles S, Sobek M. Integrated public use microdata series: version 2.0. Minneapolis: Historical Census Projects, University of Minnesota, 1997.

22 Blendon R, Scheck A, Donelan K, Hill C, Smith M, Beatrice D, et al. How white and African Americans view their health and social problems. JAMA 1995;273:341-5.

23 Fowler F Jr. Survey research methods, 2nd ed. Newbury Park: Sage, 1993.

24 Kerlikowske K, Grady D, Rubin SM, Sandrock C, Ernster V. Efficacy of screening mammography. A meta-analysis. JAMA 1995;273:149-54.

25 Nystrom L, Rutqvist L, Wall S, Lindgren A, Lindqvist M, Ryden S, et al. Breast cancer screening with mammography: overview of Swedish randomized trials. Lancet 1993;341:973-8.

26 Gotzsche $\mathrm{P}$, Olsen $\mathrm{O}$. Is screening for breast cancer with mammography justifiable? Lancet 2000;355:129-34.

27 Kerlikowskie K, Grady D, Barclay J, Sickles E, Ernster V. Effect of age, breast density and family history on the sensitivity of first screening mammography. JAMA 1996;276:33-8.

28 McGinnis J, Foege W. Actual causes of death in the United States. JAMA 1993;270:2207-12.

29 Burman M, Taplin S, Herta D, Elmore J. Effect of false-positive mammograms on interval breast cancer screening in a health maintenance organization. Ann Intern Med 1999;131:1-6.

(Accepted 15 March 2000)

\title{
Views of elderly people on living wills: interview study
}

\author{
Rebekah Schiff, Chakravarthi Rajkumar, Christopher Bulpitt
}

Editorial by

Emanuel

Care of the Elderly, Imperial College School of Medicine, Hammersmith Hospital, London W12 0NN

Rebekah Schiff clinical research fellow Chakravarthi Rajkumar senior lecturer Christopher Bulpitt professor

Correspondence to:

R Schiff

rebekah@rspscomp. demon.co.uk

BMJ 2000;320:1640-1

\section{Participants, methods, and results}

Seventy four out of 76 medical inpatients approached answered a questionnaire administered by one interviewer (RS) at two hospitals in London. All participants were aged over 65 and had a normal score on the abbreviated mental test. Ethical approval had been obtained.

The participants' mean age was 81 (range 66-97) years; 73 participants were white and one was Asian (lack of fluency in English precluded other eligible people). Most lived in independent housing (69; 93\%), either alone $(44 ; 64 \%)$ or with family members $(25$; $36 \%$ ). One participant was wheelchair dependent; others could walk: 25 (34\%) independently, $26(35 \%)$ with sticks, $22(30 \%)$ with a frame. Half received home help. Of 69 participants who completed the BASDEC depression profile, 11 had a score of 7 or above, ${ }^{4}$ suggesting depression.
Sixty one participants $(82 \%$; $95 \%$ confidence interval $72 \%$ to $90 \%$ ) had not heard of living wills, advance directives, or advance statements. Of the 13 people who said they had heard of living wills, only four correctly defined them; most, as previously noted, ${ }^{3}$ thought that the term applied to financial arrangements after death.

Most people chose relatives as a healthcare proxy:12 (17\%; $9 \%$ to $27 \%)$ chose their spouse and 45 $(63 \% ; 50 \%$ to $73 \%)$ chose other relatives; friends $(\mathrm{n}=4$ $(6 \% ; 2 \%$ to $13 \%)$ and doctors $(\mathrm{n}=16(22 \% ; 13 \%$ to $34 \%)$ were also nominated. People were specific as to which family member they would wish consulted. Five of 17 people living with their spouse $(29 \% ; 10 \%$ to $56 \%$ ) did not choose them as a healthcare proxy. They stated it was not fair to expect them to make these types of decisions; they would be too emotional to be rational and they would not make the decision the participant would have wanted. Seventeen $(24 \% ; 14 \%$ to $35 \%$ ) had discussed issues surrounding medical care with their proposed healthcare proxies.

Our elderly participants found many disabilities unacceptable, stating that they preferred "comfort only" care, even if they might die, to active treatment (table). The single condition most feared was advanced dementia ( $\mathrm{n}=56(78 \% ; 66 \%$ to $87 \%)$, and this became even less acceptable when combined with other disabilities. Least feared was being in a wheelchair $(\mathrm{n}=17(24 \% ; 14 \%$ to $35 \%)$. Women were less likely than men to request active treatment options: geometric mean (out of 27 disabilities) 3.2 for women, 6.5 for men; ratio difference $=2.0(1.1$ to $3.8 ; \mathrm{P}=0.04)$ after adjustment for age. 